\title{
FIBRA DE BURITI (MAURITIA FLEXUOSA MART.): CARACTERÍSTICAS E APLICAÇÕES
}

\author{
Regina Célia de Sousa \\ Universidade Federal do Maranhão \\ sregina@ufma.br \\ Nayara Chaves Ferreira Perpétuo \\ Instituto Federal do Maranhão \\ nayara_chaves@hotmail.com
}

Resumo: O buriti é uma palmeira de grande importância para as comunidades rurais onde ela ocorre, devido, principalmente, ao uso múltiplo de suas partes. A polpa do fruto do buriti, por exemplo, é utilizada na fabricação de doces, licores e outros, já as folhas mais novas são utilizadas na produção de peças artesanais. Este trabalho teve como objetivo a realização de uma pesquisa bibliográfica sobre a extração e utilização da fibra de buriti, popularmente denominada de linho, na confecção de artigos artesanais. Este estudo pretende orientar novas pesquisas de caracterização física, química e mecânica da fibra de linho do buriti visando melhorar a qualidade de produtos artesanais tradicionais e o desenvolvimento de novos produtos para utilização em design, buscando principalmente a diminuição do grau de molhabilidade dessas fibras.

Palavras-chave: Fibra vegetal, buriti, produtos artesanais.

\begin{abstract}
Buriti is a very important palm to the rural communities where it occurs, mainly due to the multiple usages of its parts. For example, the pulp of the fruit is used to produce sweets, liqueurs and others. The newest leaves are used in the production of handicrafts. The aim of this study is to conduct an extensive literature review on the extraction and use of buriti fiber, commonly named "linho", in the manufacture of handmade articles. Moreover, this study intend to guide further research on physical, chemical and mechanical properties of the buriti fiber in order to improve the quality of traditional craft products, and the development of new products for use in design, mainly seeking the decrease of wettability degree of these fibers.
\end{abstract}

Keywords: Vegetable fiber, buriti, handmade products. 


\section{INTRODUÇÃO}

Conforme a designer Raquel Noronha (2011) entender os materiais disponíveis viabiliza não somente a ação de projetar, mas também expõe o contexto onde eles estão inseridos e coloca, muitas vezes, o designer como mediador de elementos sociais, ambientais e econômicos. É a partir do compartilhamento dessa noção que este trabalho por meio da interdisciplinaridade, característica do design, dedica-se a explorar a área de materiais de modo a conhecer as características da matéria prima utilizada - linho de buriti.

Este profissional, no exercício de sua função pode tomar atitudes conscientes voltadas, por exemplo, para o uso de materiais de menor impacto, recicláveis e biodegradáveis. Para isso, deve conhecer em profundidade os materiais que utiliza, pois somente assim será capaz de avaliar o risco que eles representam. Munido de informações sobre os materiais, o designer pode melhor estudar todas as possibilidades e avaliar as possibilidades de mudanças que promovam melhorias.

Adélia Borges (2011) ao fazer um levantamento das diversas experiências de atuação do design no artesanato em território nacional trata como ação bem sucedida a melhoria das condições técnicas a partir do estudo das potencialidades das matériasprimas, permitindo o melhor planejamento de seu uso e o conhecimento de suas restrições de uso e manutenção.

Normalmente a pesquisa sobre materiais autóctones no país é colocada em segundo plano e, em parte, deve-se ao foco dos estudos de engenharia dos materiais voltarem-se aos materiais industriais de maior interesse econômico. Contra essa tendência e por vislumbrar, a partir da melhoria das condições técnicas, novas possibilidades para artesãos e meio-ambiente está a motivação para esta pesquisa.

Aqui dedica-se a uma matéria prima específica: a palmeira buriti (Mauritia flexuosa L.). Seu nome tem origem indígena - "biriti", que em tupi-guarani significa "árvore que emite líquido", "aquela que contém água", a "árvore da vida" (GUIMARÃES, 2014). A nomenclatura é bastante pertinente uma vez que faz parte de um grupo vegetal com alto índice de aproveitamento, bem como estratégica para a manutenção do ecossistema no qual se insere.

Dentre as diversas necessidades do ser humano atendidas por essa palmeira está a alimentação; a polpa do buriti é muito usada na preparação de doces, sucos e licores, entre outros; as folhas mais novas e os pecíolos são utilizados na produção de artigos artesanais, tais como, bolsas, redes, brinquedos e canoas; as palhas (folhas secas sem o pecíolo) são usadas para fazer coberturas de casas; e a palmeira pode ainda ser utilizada no paisagismo. Em todas as situações, os produtos gerados são utilizados para uso próprio e para venda, gerando renda (LORENZI et al., 2010; SARAIVA \& FERNANDES-PINTO, 2007; PASSOS \& MENDONÇA, 2006;LEAL, 2005; RIGUEIRA et al., 2002).

Ela ocorre na América do Sul, mais precisamente na Colômbia, Equador, Peru, Venezuela, Brasil e Guianas, além de Trinidad e Tobago. No Brasil, onde é considerada uma das palmeiras mais abundantes, é encontrada em toda Amazônia, Brasil Central, Bahia, Ceará, Maranhão, Piauí, Minas Gerais, e São Paulo. Os buritizais ocorrem em terrenos baixos de florestas abertas e fechadas, em solos pouco drenados, brejosos ou inundados (HENDERSON et al., 1995; LORENZI et al., 2004; SARAIVA, 2009). 
O buriti é uma palmeira dióica, possuindo um único estipe, que quando adultas pode atingir $40 \mathrm{~m}$ de altura e diâmetro de $60 \mathrm{~cm}$. As palmeiras adultas possuem entre 8 a 20 folhas, atingindo até $2,5 \mathrm{~m}$ de envergadura com pecíolos de até $4,5 \mathrm{~m}$ de comprimento (HOLM et al., 2008; LORENZI et al., 2004;CARDOSO et at., 2002; HENDERSON et al., 1995;). Na fase jovem, elas possuem apenas folhas sobre o chão, à medida que evoluem, a formação do tronco é iniciada, sendo coberto de pecíolos, que se mantem presos ao tronco por período relativamente longo. Durante o crescimento, as folhas antigas caem, exibindo o estipe permanente (SARAIVA, 2009).

As folhas mais novas da palmeira de buriti denominadas "olho" ou "ponteira", são utilizadas para retirar a fibra chamada de "linho do buriti", tida como nobre devido a mesma ser delicada e resistente (SARAIVA, 2009).

Dessa fibra são fabricados produtos artesanais que são extremamente finos e delicados. Os mais comuns são leques, esteiras, redes, chapéus, toalhas, bolsas, cordas. Seus traços característicos são identificadores da cultura desenvolvidas em torno dessa palmeira, principalmente nas regiões Norte e Nordeste do Brasil, podendo ser considerado único no país.

A cadeia produtiva do artesanato feito a partir do linho de buriti tem papéis bastante demarcados, sendo a coleta feita predominantemente por homens e o beneficiamento e confecção das peças realizado por mão-de-obra predominantemente feminina.

Com exceção de 2009, quando a produção de linho de buriti atingiu 803 toneladas, essa produção tem se mantido um pouco abaixo de 500 toneladas/ano (IBGE, 2014). Em contrapartida, a procura, produção e comercialização do artesanato do buriti se encontram em ascendente, em especial nas regiões dos Lençóis Maranhenses, com aumento no número de coletores e artesãos (RIGUEIRA et al., 2002).

A procura dos produtos artesanais de fibra de buriti vem sendo estimulada principalmente pelo aumento do turismo, da procura por produtos fabricados com material natural, provenientes de comunidades rurais e tidos como socialmente justos, entre outros (SARAIVA, 2009).

O descompasso entre a produção de fibras de linho do buriti e a produção de artesanatos, mostra que está ocorrendo uma exaustão dos buritizais, em especiais aqueles de mais fácil acesso e/ou próximos às comunidades envolvidas no mercado, que mostram visualmente o declínio e morte das palmeiras (FERNANDES-PINTO \& SARAIVA, 2006).

As novas demandas de mercado apontam para a necessidade da busca de possibilidades técnicas visando aumentar a qualidade de produtos artesanais já produzidos e a criação de novos produtos, em especial os feitos de fibra de linho de buriti. O objetivo principal é aumentar o valor agregado e ajudar a manter os buritizais, visto que uma maior capitalização dos coletores e artesãos dará tempo aos buritizeiros se recuperarem das retiradas dos "olhos". É evidente que essa ação isolada pode não alcançar o sucesso, é importante que sejam trabalhados paralelamente a conscientização da preservação ambiental e noções de economia visando com isso um manejo organizado do extrativismo da cadeia do buriti por associações de pessoas conscientes e vigilantes.

Uma das principais características apresentada pelas fibras naturais de origem vegetal, tais como as de buriti, é o elevado índice de absorção de água, o que restringe 
a sua utilização em alguns tipos de produtos, em especial para vestimenta que precisa de lavagem sistematicamente. Deste modo, o principal objetivo deste estudo consistiu em reunir o que já foi estudado sobre a fibra de linho de buriti e suas aplicações em produtos artesanais, visando uma pesquisa futura com relação a caracterização física e mecânica e a utilização de técnicas já existentes para diminuir o caráter hidrofílico dessas fibras. A metodologia empregada consistiu de revisão bibliográfica acerca do tema tratado, sendo que as informações foram obtidas de fontes tais como livros, dissertações, teses e artigos científicos.

\section{DESENVOLVIMENTO}

\subsection{A palmeira do buriti}

O buriti (Mauritia flexuosa L.) é uma palmeira da família Arecaceae e o nome Mauritia é uma homenagem ao Conde Mauricio de Nassau, governador da Província de Pernambuco no período da invasão holandesa no Brasil (LORENZI, 2010). Ela encontra-se distribuída em grande parte da América do Sul. No Brasil, onde é considerada a mais abundante, ocorre nos estados do Pará, Amazonas, Amapá, Rondônia, Goiás, Tocantins, Distrito Federal, Bahia, Minas Gerais, Mato Grosso, Ceará, Piauí e Maranhão (SANTELLI, 2005).

Os buritizais se localizam em regiões de brejo ou permanentemente inundadas, formando agrupamentos quase homogêneos e também conhecidos como veredas de buritizais (SILVA, 2009, LEAL, 2005). Por se encontrar amplamente distribuída no Brasil, a palmeira do Buriti representa um grande potencial econômico em diferentes regiões, em especial na região Nordeste.

Os buritizais são de grande importância para a populações locais, pois é fonte de alimento, abrigo e renda, ocasionado pelo múltiplos gama de utilização de suas partes. Eles possuem um papel fundamental no equilíbrio dos ecossistemas locais, pois contribuem para manter a umidade do solo e dos corpos hídricos, em especial nos períodos de seca. Retêm o assoreamento dos rios e constituem local de habitação, abrigo e fonte de alimento para diversos animais. A destruição de buritizais leva a diminuição na oferta hídrica (FERNANDES-PINTO \& SARAIVA, 2006).

A palmeira do buriti possui tronco cilíndrico e solitário, é robusta e ereta podendo atingir $40 \mathrm{~m}$ de altura e diâmetro com até $60 \mathrm{~cm}$. As suas imensas folhas em forma de leque e os pecíolos podem atingir 7 e 4,5 m de comprimento, respectivamente (MARTINS \& FILGUEIRAS, 2006; LEAL, 2005). A frutificação dessa palmeira ocorre somente quando, na mesma área, existe exemplares machos e fêmeas, pois existem indivíduos com flores masculinas e indivíduos com flores femininas e hermafroditas (CARNEIRO et al., 2011).

A palmeira de buriti possui numerosas brácteas pedunculares tubulares com até $12 \mathrm{~cm}$ de comprimento envolvendo todo o pedúnculo, que tem cerca de $30 \mathrm{~cm}$ de comprimento. Produz em média cinco inflorescências interfoliar por ano, ramificada em primeira ordem, tendo de 27 a 35 ramificações, com 2,5 a 4 m de comprimento. As pistiladas (fêmea) produzem em média 3500 flores e as estaminada (macho) na ordem de 200. As ráquilas estaminadas estão presentes em número que varia de 47 a 56 . As flores estaminadas são amarelas ou alaranjadas, naviculares a fusiformes, assimétricas e sésseis, medem de 0,8 a 1,2 cm de comprimento e 0,4 a 0,6 cm de largura. 0 número 
de ráquilas pistiladas varia entre 45 a 47, sustentando de 3 a 8 flores pistiladas, solitária e aos pares. Essas flores são creme amareladas, naviculares, assimétricas, sésseis. Geralmente, o buriti floresce de novembro a abril. Na região do cerrado ele floresce de março a maio (MARTINS \& FILGUEIRAS, 2006; LEAL, 2005; SARAIVA, 2009).

As folhas de 20 a 30 unidades distribuídas na coroa, são dispostas em forma de leque ou costopalmadas e podem atingir $7 \mathrm{~m}$ de comprimento. Popularmente as folhas de buriti são divididas em talo (pecíolo) e palha, sendo que, a parte mais larga do talo e que fixa a folha ao tronco, é chamada de capemba. O pecíolo pode atingir até 4,5 $\mathrm{m}$ de comprimento e é coberto por uma fibra dura, conhecida como tala. A palha é o restante da folha (SAMPAIO, 2011).

O fruto do buriti são do tipo drupa, medindo de 4 a $5 \mathrm{~cm}$ de comprimento, possuindo a forma elipsoide e cor castanho-avermelhado; possui epicarpo (casca) formado por escamas duras sobrepostas e envernizadas, o mesocarpo (polpa) é relativamente espesso, amarelado ou alaranjado, duro e rico em pró-vitamina $A$, betacaroteno e ácido oléico; o endocarpo (carroço) possui uma semente escura e globóide de até $2 \mathrm{~cm}$ de diâmetro (MARTINS \& FILGUEIRAS, 2006; LEAL, 2005, ALBUQUERQUE et al. 2005, ABREU, 2001; MARIATH et al., 1989). De acordo com Manhães (2007), a composição é de $30 \%$ de casca, $10 \%$ de polpa, $20 \%$ de envoltório celulósico e $40 \%$ de caroço. A polpa é muito empregada na produção de doces, geleias, sucos, licores e sorvetes. O resíduo que sobra do processamento desses produtos, denominado popularmente de bagaço, é utilizado como adubo em roças e hortas. Tido como produto de grande valor agregado, o óleo extraído da polpa, que é comestível, possui várias substâncias de grande importância para saúde humana (LEAL, 2005). Ao caírem na água, eles podem ser deslocados dispersando a espécie na região. Os frutos que não são recolhidos pelos catadores, podem servir de alimento para diversos animais, tais cotias, capivaras e araras, que colaboram para disseminar as sementes.

A frutificação do buriti ocorre geralmente no segundo semestre do ano na maioria das regiões. Em média, uma palmeira produz anualmente $200 \mathrm{~kg}$ de fruto, sendo que em um hectare existem em média 64 palmeiras, resultando em uma produtividade média de 12,8 toneladas de fruto por hectare ao ano. No cerrado o buriti apresenta frutos durante quase todo o ano, no Distrito Federal ficam maduros no final de julho. Em um mesmo buritizal, a maturação dos frutos de buriti pode ser heterogênea, podendo acontecer de 7 a 11 meses. (LORENZI et al., 2004).

\subsection{A fibra linho de buriti}

$\mathrm{Na}$ relação estabelecida entre designers e artesãos, Adélia Borges (2011) aponta que mais do que ensinar, os designers aprendem com o artesão. Entender essa relação como uma troca faz com que tenhamos o entendimento de que os saberes acadêmicos e populares se complementam ao tratarmos da produção artesanal.

Nessa perspectiva designers pesquisadores mapeiam in loco a cadeia produtiva de comunidades artesãs que trabalham com o linho da fibra de buriti (NORONHA, 2011; GUIMARÃES, 2014). Esse contato possibilita além do reconhecimento da prática uma oportunidade para melhorias tanto no manejo da matéria prima, como nos produtos desenvolvidos. 
A folha que ainda não se abriu (meristema apical da palmeira) é denominada popularmente de "olho de buriti" e dela é retirado o broto do buriti. O "olho" é coletado no alto dos pés após a exposição do pecíolo da folha nova (chamada regionalmente de "canela") e antes da abertura da palha (SARAIVA, 2009).

O manejo de retirada dessas folhas, deve obedecer uma certa periodicidade para não danificar a palmeira, que pode chegar a morte. De acordo com o conhecimento popular não se pode retirar dois "olhos" seguidos de uma mesma palmeira de buriti. Após a retirada de um "olho", tem que se esperar que uma outra folha nova se desenvolva, havendo tempo suficiente assim para a paleira se recompor. Em média uma palmeira de buriti desenvolve três "olhos" por ano, sendo recomendado que se faça apenas uma retirada de um "olho" a cada 8 meses em uma mesma palmeira. Entretanto, deve-se respeitar as características locais que podem apresentar variações temporais dessas propriedades (VIEIRA et al., 2011, CATTANI \& BARUQUE-RAMOS, 2014).

Após a remoção dos brotos do "olho", o linho ou seda de buriti e a borra são retirados fazendo-se a abertura dos seus folíolos. O linho é a fibra mais fina, delicada e resistente, já a borra é a fibra mais grossa e menos resistente que o linho. Os produtos artesanais mais nobres, mais elaborados e mais valorizados (toalhas e caminhos de mesa, entre outros), são feitos apenas com fibras de linho. Outros são feitos com a mistura dessas duas fibras (tapete que é a base para bolsas, pastas, jogos americanos e outros) e, existem os que são feitos somente de borra (descanso de panela e tapetes feitos com a técnica de trança) (SARAIVA, 2009).

É importante que após a retirada do olho a extração do linho seja mais breve possível, garantindo a qualidade final da fibra que será usada na manufatura dos produtos e quando não for possível os "olhos" devem ser acondicionados em local protegido da luz solar, evitando assim o ressecamento da fibra que inviabiliza a extração correta (GUIMARÃES, 2014).

Em mapeamento da cadeia produtiva foi identificado que a cada dois "olhos" são gerados dois sacos de linho. A retirada dessas fibras, desfiando os brotos, é feita com a ajuda de uma faca, onde uma leve incisão é realizada na superfície do folíolo e uma fina película é puxada. Esse processo é repetido até que o folíolo seja todo consumido. Ao final do processo, os fios são cozidos em água, podendo ainda nessa etapa, serem tingidos com corantes (NORONHA, 2011).

O cozimento permite a maleabilidade necessária na confecção de peças artesanais. O tempo desde o momento da fervura garante maior vivacidade às cores dos corantes, mas também podem enfraquecer a fibra deixando-a quebradiça e inviável para a possibilidade de ser empregada na manufatura das técnicas artesanais que exigem maior resistência mecânica, tais como o macramê e tecelagem por batimento e carreira (GUIMARÃES, 2014).

A secagem do fio natural pode ser feita ao sol ou à sombra e o fio tingido preferencialmente à sombra, sob o risco de comprometer o resultado final da cor escolhida. Depois de seca a fibra é beneficiada de acordo com a técnica a ser utilizada para a confecção dos produtos.

Normalmente a produção volta-se para artefatos que não precisam de manutenção contínua, principalmente no que diz respeito à lavagens em detrimento da própria estrutura do material. 


\subsection{Fibras vegetais}

As fibras naturais de origem vegetais são longas quando comparadas com o seu diâmetro e possuem secção transversal vazada e arredondadas. Elas estão distribuídas por todo vegetal e, de acordo com a origem anatômica, são classificadas em fibras de talo, de folha, de lenho e de superfície. Uma mesma planta pode fornecer diferentes tipos de fibras, como o caso do buriti, onde fibras são retiradas das folhas novas e do pecíolo (MONTEIRO et al., 2009).

As fibras vegetais, também denominadas de lignocelulósicas, são constituídas basicamente das substâncias polares celulose, hemicelulose e lignina, além de fração de solúveis (pectina, sais inorgânicos, substâncias nitrogenadas, corantes naturais) (BENINI, 2011). A celulose é um polímero natural de cadeia longa composto de um só monômero (glicose) e classificado como polissacarídeo ou carboidrato. A unidade elementar da macromolécula de celulose contém três radicais hidroxilas que formam ligações de hidrogênio dentro das moléculas, tornando a celulose altamente hidrofílica (AGARWAL \&BROUTMAN, 2000). A hemicelulose constitui grupos distintos de polissacarídeos formados por vários açúcares incluindo glicose, xilose, galactose, arabinose e manose. A hemicelulose contém várias unidades de açúcares, apresenta ramificação de cadeias poliméricas e o grau de polimerização é relativamente pequeno. Ela geralmente atua ligando a celulose à lignina. Enquanto os constituintes da celulose independem da planta, os da hemicelulose diferem de planta para planta (AGARWAL \&BROUTMAN, 2000). A lignina, substância hidrofóbica, é um polímero complexo de estrutura amorfa que une as fibras celulósicas formando a parede celular. Fornece resistência à compressão ao tecido celular e às fibras, enrijecendo a parede celular e protegendo os carboidratos (açúcares) contra danos físicos e químicos (BLEDZKI \& GASSAN, 1999). A região de cultivo, as condições climáticas e o tipo de solo podem influenciar na composição química das fibras vegetais (PEZZOLO, 2012).

Feixes de moléculas de celulose se juntam formando microfibrilas, que possuem regiões cristalinas (ordenadas) e regiões amorfas (menos ordenadas), que se alternam. As microfibrilas agregadas formam fibrilas, que juntas formam as fibras celulósicas. Nas fibras vegetais as microfibrilas estão dispostas em camadas de diferentes espessuras e ângulos de orientação. As células das fibras são compostas por quatro camadas de microfibrilas, as mais externas de estrutura reticulada e as internas em forma de espiral. No interior da célula há uma cavidade central de seção elíptica denominada lúmen. A região central da fibra também pode apresentar uma cavidade chamada lacuna que, juntamente com os lumens, é responsável pela grande incidência de poros permeáveis nas fibras, o que causa elevada absorção de água (JUNIOR, 2000).

As propriedades físicas das fibras vegetais são determinadas principalmente pela composição química e física, tais como a estrutura das fibras, celulose, ângulo das fibrilas e pelo grau de polimerização. A hemicelulose não está diretamente correlacionada à resistência e a dureza, já a concentração de lignina influência a estrutura, as propriedades, a morfologia, a flexibilidade e a taxa de hidrólise (AGARWAL \&BROUTMAN, 2000). As fibras de buriti, materiais oriundo de fonte renovável, podem ser uma interessante opção como material para engenharia de materiais, otimizando sua aplicabilidade. 


\subsection{Tratamento de fibras vegetais}

A utilização de fibras vegetais em aplicações mais técnicas e mais elaboradas é dificultada pelas consideráveis variações de valores em suas propriedades mecânicas e composição, tornando necessário a realização de modificações das mesmas com fins específicos de homogeneizar propriedades. A natureza hidrofílica afeta as propriedades mecânicas das fibras vegetais, entretanto essa propriedade pode ser alterada através da modificação superficial das fibras por métodos físicos ou químicos (BLEDZKI \& GASSAN, 1999).

Tratamentos físicos, tais como tratamento térmico, descarga elétrica corona e plasma, atuam na superfície das fibras e geram mudanças estruturais. Já os tratamentos químicos podem alcançar camadas mais internas das fibras. Tratamentos alcalinos, como isocianeto, acetilação, mercerização, entre outros, tem sido citados na literatura (BLEDZKI \& GASSAN, 1999, SAHEB \& JOG, 1999).

Barbosa (2011) analisou as características morfológicas e as propriedades mecânicas e térmicas da fibra de buriti (retirada do pecíolo) e de compósitos em matriz epóxi e poliéster com adição da fibra, e entre os seus resultados concluiu que quanto menores os diâmetros da fibra maiores são a densidade, Módulo de Elasticidade e resistência à tração; as fibras tornaram-se mais frágeis, quanto maiores as doses de irradiação gama e; ensaios Charpy e de Pullout revelaram que a energia de impacto aumentou de 20 a 30\% quando comparada com outras fibras lignocelulósicas.

Sampaio (2013) demonstrou que a utilização de plasma indutivo de metano e de heptano pode ser aplicada com sucesso para modificar a superfície de fibras de celulose obtidas de papel vegetal comercial. O objetivo principal era criar um revestimento capaz de reduzir a hidrofilicidade das fibras de celulose. O estudo mostrou que o tratamento com heptano a $30 \mathrm{~W}$ por 20 minutos originou o melhor revestimento em termos de estabilidade e homogeneidade da fibra de celulose. Os resultados mostram que os tratamentos foram capazes de aumentar a hidrofobicidade das fibras e que a tensão interna dos recobrimentos provoca a sua fragmentação, aumentando com a potência do reator e com a espessura do filme.

\section{CONCLUSÃO}

Existe uma preocupação quanto ao futuro dos buritizais, pois, nos últimos anos, é visível pelas comunidades locais, a diminuição do tamanho dos "olhos" e a morte das palmeiras, e como consequência a redução da oferta de água em pequenos riachos. Isso torna urgente não só uma adequação das práticas de manejo e de controle da atividade, como também o desenvolvimento de tecnologias que aumentem o valor agregados dos produtos fabricados com as partes da palmeira do buriti, em especial com a fibra linho de buriti.

Embora o conhecimento comunitário acerca da produção e utilização das fibras de buriti seja muito extenso e bem descrito na literatura, as perspectivas futuras para o aumento da renumeração dentro da cadeia de valor do buriti, com base em análises de propriedades físicas, químicas e mecânicas, esbarram em um grande gargalo da desinformação. Assim, o presente estudo poderá ampliar o conhecimento da potencialidade do uso do buriti, em produtos têxteis, artesanais e/ou industriais apresentando as principais informações sobre essa palmeira e a fibra linho de buriti. 


\section{REFERÊNCIAS}

ABREU, Solange Aparecida Brienza de. Biologia Reprodutiva de Mauritia flexuosa L. (Arecaceae) em Vereda no Município de Uberlândia-MG. 2001. 87 f. Dissertação (mestrado) - Universidade Federal de Uberlândia, Curso de Pós-Graduação em Ecologia e Conservação de Recursos Naturais.

AGRAWAL, Bhagwan Das; BROUTMAN, Lawrence John. Analysis and Performance of Fiber Composites, Nova York: John Wiley \& Sons, 2000.

ALBUQUERQUE, Marcos Lázaro Souza et al. Characterization of Buriti (Mauritia flexuosa L.) Oil by Absorption and Emission Spectroscopies. Journal of the Brazilian Chemical Society, São Paulo, v. 16, n. 6A, p. 1113-1117, 2005.

BARBOSA, Anderson de Pula. Características estruturais e propriedades de compósitos poliméricos reforçados com fibras de buriti. 2011. $141 \mathrm{f}$. Tese (doutorado) - Universidade Estadual do Norte Fluminense Darcy Ribeiro, Curso de Pós-Graduação em Engenharia e Ciência dos Materiais.

BENINI, Kelly Cristina Coelho de Carvalho. Desenvolvimento e caracterização de compósitos poliméricos reforçados com fibras lignocelulósicas: HIPS/fibras da casca de coco verde e bagaço de cana de açúcar. 2011. 125f. Dissertação (mestrado) Universidade Estadual Paulista - Guaratinguetá, Curso de Pós-Graduação em Engenharia Mecânica.

BLEDZDI, Andrzej K.; GASSAN, Jochen. Composites reinforced with celulose based fibres. Progress in Polymer Science, v. 24, n. 2, p. 221-274, 1999.

BORGES, Adélia. DESIGN + ARTESANATO - O Caminho Brasileiro. São Paulo: Terceiro Nome, 2011.

CARDOSO, Grace de Lourdes; ARAÚJO, Glein Monteiro de; SILVA, Selma Aparecida da Estrutura e Dinâmica de uma População de Mauritia flexuosa (Arecaceae) em Vereda na Estação Ecológica do Panga. Boletim do Herbário Ezequias Paulo Heringer. Uberlândia, v. 9, p. 34-48, 2002.

CARNEIRO, Fernando José Costa; RANGEL, José Hilton Gomes; LIMA, Joselia Maria Ribeiro. Construção de modelos moleculares para o ensino de química utilizando a fibra de buriti. Revista ACTA Tecnológica - Revista Científica, São Luis, v. 6, n. 1, p. 1726, 2011.

CATTANI, Ivete Maria; BARUQUE-RAMOS, Júlia. Fibra de buriti (Mauritia flexuosa Mart.) e aplicações em produtos têxteis. In: 2 CONGRESSO CIENTÍFICO TÊXTIL E DE MODA, 2014, São Paulo, Anais...São Paulo: ABTT, 2014, p. 1-14.

FERNANDES-PINTO, Érika; SARAIVA, Nicholas Allain. Fauna silvestre associada a buritizais - etnoecologia e conservação em uma região do semi-árido Maranhense. In: VII CONGRESSO INTERNACIONAL SOBRE MANEJO DE FAUNA SILVESTRE NA AMAZÔNIA E AMÉRICA LATINA, 2006, Ilhéus. Resumo...Ilhéus: 2006. p. 491 - 491.

GUIMARÃES, Márcio James. Contribuições do Design para o desenvolvimento sustentável da produção artesanal. 2014. 69 f. Dissertação (mestrado) - Universidade Federal do Maranhão, Programa de Pós-Graduação em Design. 
HENDERSON, Andrew; BECK, Hans T.; SCARIOT, Aldicir. Flora de palmeiras da llha de Marajó. Boletim do Museu Paraense Emílio Goeldi, sérieBotânica. Belém, v. 7(2), p. 199-221, 1991.

HOLM, Jennifer A.; MILLER, Christopher J.; CROPPER Jr, Wendell P. Population Dynamics of the Dioecious Amazonian Palm Mauritia flexuosa: Simulation Analysis of Sustainable Harvesting. Biotropica, v. 40(5), p. 550-558, 2008.

IBGE, Instituto Brasileiro de Geografia e Estatística. (2014). Produção da Extração Vegetal e da Silvicultura, Diretoria de Pesquisas, Coordenação de Agropecuária. Disponível em: http://www.sidra.ibge.gov.br/. Acessado em: 04/abril/2016.

JÚNIOR, Holmer Savastano. Materiais à base de cimento reforçados com fibra vegetal: reciclagem de resíduos para construção de baixo custo. 2000, 52 f.Tese (livre docência) - Universidade de São Paulo, Departamento de Engenharia de Construção Civil.

LEAL, Adão Firmino. Condições do extrativismo e aproveitamento das frutas nativas da microrregião de Teresina - Piauí. 2005, 93 f. Dissertação (mestrado) - Universidade Federal do Piauí, Curso de Pós-Graduação em Desenvolvimento e Meio Ambiente.

LORENZI, Harri et al. Palmeiras brasileiras e exóticas cultivadas. Nova Odessa: Instituto Plantarum de Estudos da Florida, 2004.

LORENZI, Harri et al. Flora Brasileira - Aracaceae (Palmeiras). Nova Odessa: Instituto Plantarum de Estudos da Florida, 2010.

MANHÃES, Luciana Ribeiro Trajano. Caracterização da polpa de buriti (Mauritia flexuosa): um potente alimento funcional. 2007. 78 f. Dissertação (mestrado) Universidade Federal Rural do Rio de Janeiro, Curso de Pós-Graduação em Ciência e Tecnologia de Alimentos.

MARIATH, José Guilherme Rains; LIMA, Magnolia C. C.; SANTOS, Leonor Maria Pacheco. Vitamin A activity of buriti (Mauritia vinifera Mart) and its effectiveness in the treatment and prevention of xerophthalmia. American Journal of Clinical Nutrition, 1989 , v. 49 , p. 849-853.

MARTINS, Renata Corrêa; FILGUEIRAS, Tarciso de Sousa. Arecaceae. In: CAVALCANTI, Taciana Barbosa (org). Flora dos Distrito Federal. Brasília: Embrapa Recursos genéticos e biotecnologia. 2006.

MONTEIRO, Sérgio Neves et al. Statistical analysis to characterize the uniformity of mechanical properties of butiti fibers. In: Characterization of Mineral, Metals \& Materials, 2009, San Francisco. Proceedings... San Francisco: TMS, 2009, p. 1-8.

NORONHA, Raquel Gomes (org.). Identidade é valor: as cadeias produtivas do artesanato de Alcântara. São Luís: EDUFMA, 2011.

PASSOS, Mahedy Araújo Bastos; MENDONÇA, Maria Sílvia de; Epiderme dos segmentos foliares de Mauritia Flexuosa L. f. (Arecaceae) em três fases de desenvolvimento. Acta Amazônica, Manaus, vol. 36(4), p. 431-436, 2006.

PEZZOLO, Dinah Bueno. Tecidos - Histórias, tramas, tipos e usos. São Paulo: SENAC, 2012. 
RIGUEIRA, Sabrina, et al. Projeto Buriti: artesanato, natureza e sociedade. 2002. Instituto Terra Brasilis de Desenvolvimento Sócio-Ambiental. Belo Horizonte.

SAHED, D. Nabi; JOG, Jyoti P. Natural fiber polymer composites: a review. Advances in Polymer Technology, v. 18, n. 4, p. 351 -363, 1999.

SAMPAIO, Maurício Bonesso. Boas práticas de manejo para o extrativismo sustentável do buriti. Brasília: Instituto Sociedade, População e Natureza, 2011.

SAMPAIO, Juliana Abrantes. Caracterização de fibras de celulose recobertas por plasma. 2013. 42 f. Monografia (Graduação), Curso de Engenharia de Materiais, Escola Politécnica, Universidade Federal do Rio de Janeiro.

SANTELLI, Paulo. Fisiologia Pós-colheita de frutos das palmeiras Syagrus oleracea (Mart.) Becc. e Mauritia vinifera Mart. 2005. 86 f. Dissertação (mestrado) Universidade de Brasília, Programa de pós-graduação em Botânica.

SARAIVA, Nicholas Allain; FERNANDES-PINTO, Érika. Extrativismo, Economia Solidária e Desenvolvimento Sustentável na Região dos Lençóis Maranhenses. In: V ENCONTRO INTERNACIONAL DE ECONOMIA SOLIDÁRIA: O Discurso e a Prática da Economia Solidária, 2007, São Paulo. Anais... São Paulo: NESOL-USP, 2007. p. 1-18.

SARAIVA, Nicholas Allain. Manejo Sustentável e Potencial Econômico da Extração do Buriti nos Lençóis Maranhenses. 2009. 129 f. Dissertação (Mestrado) - Universidade de Brasília, Centro de Desenvolvimento Sustentável.

SILVA, Paulo Antonio. Orthopsittaca manilata (Boddaert, 1783) (Aves: Psittacidae): abundância e atividade alimentar em relação à frutificação de Mauritia flexuosa L. f. (Arecaceae) numa vereda no Triângulo Mineiro. 2009. 71 f. Dissertação (mestrado) Universidade Federal de Uberlândia, Programa de Pós-Graduação em Ecologia e Conservação de Recursos Naturais.

VIEIRA, Débora Alvara; FACÓ, Luciana Rodrigues; CECY, Adriana. BURITI: Um fruto do cerrado considerado uma plant de uso múltiplo. Cenarium Pharmacêutico, Brasília, n.4, p. 11-31, 2011. 